\title{
Intellectual Property Rights and Bilateral Intra-Industry Trade Flows: An Intuitive Framework
}

\author{
Nasser Al-Mawali \\ College of Economics and Political Science, Sultan Qaboos University, Muscat, Oman \\ Email: almawali@squ.edu.om
}

Received 6 July 2014; revised 10 August 2014; accepted 8 September 2014

Copyright (C) 2014 by author and Scientific Research Publishing Inc.

This work is licensed under the Creative Commons Attribution International License (CC BY).

http://creativecommons.org/licenses/by/4.0/

c) (i) Open Access

\begin{abstract}
The intention of this paper is to provide "for the first time" a conceptual framework on how a level of IPRs is linked to bilateral intra-industry trade (IIT) flows. The proposed analysis of the relationship between IPRs and IIT of this paper is couched in a simple and intuitive framework that answers a positive question of how intellectual property rights (IPRs-) induced market expansion, and market power effects are related to the horizontal and vertical intra-industry trade flows. The proposed intuitive framework introduces a demand-side approach and a supply-side approach in explaining the link between IPRs and intra-industry trade (IIT) flows. The supply-side approach explores how a country's IPRs affect its own exports (supply). In contrast, the demand-side approach examines the effect a country's IPRs have on its own imports (demand). The presented conceptual framework of this paper provides intuitive evidence that in determining bilateral intra-industry trade (IIT) flows in a two-country world, the demand approach posits that bilateral trade flows may increase or decrease due to improvements in IPRs in the importing destination country, while the supply-side approach states that the bilateral trade flows may also increase or decrease due to strong (high) IPRs in the exporting country. Furthermore, the simultaneous effects of both supply and demand on bilateral intra-industry trade flows are simultaneously needed in explaining the effects of strengthening the level of the IPRs on bilateral intra-industry trade flows (IIT).
\end{abstract}

\section{Keywords}

Intellectual Property Rights (IPRs), Intra-Industry Trade (IIT) 


\section{Introduction}

The issue of IPRs protection is of growing worldwide importance as economies move increasingly towards knowledge-based activities [1]. Furthermore, after the inclusion of the Agreement on Trade-Related Aspects of Intellectual Property Rights (TRIPs) in the system of the World Trade Organization (WTO), the attention paid by trade economists to IPRs issues has increased [2]. In particular, there has been ever increasing concern about the economic impact of protection for these rights, and a number of studies have analyzed the links between their protection and economic welfare, economic growth, innovations, FDI, and technology transfer. However, little work has been done directly to investigate the relationship between IPRs protection and traditional trade flows (one-way trade). It appears that no theoretical or empirical study to date has specifically attempted to trace the links between IPRs protection and two-way trade, including IIT flows.

Given the on-going concern about the importance of IPRs and the fact that about one-fourth of current world trade is an intra-industry trade [3], it is important to investigate how this particular type of trade (intra-industry trade) is related to national differences in IPRs protection regimes. It is to be expected that, the relationship between IPRs protection and IIT flows will be quite different from that when one-way trade (or inter-industry trade) is conducted. The reason for such difference is that IIT involves exchanging products within the same industry whereas inter-industry trade does not. Therefore, the existence of bilateral intra-industry trade (IIT) implies that the trading countries have the same industry pattern. This is a situation in which intellectual piracy, unauthorized use of technology, and other IPRs related issues become potentially important.

In view of the fact that the existing trade literature on IPRs and trade has unearthed the possible links between IPRs protection and IIT, this paper presents a conceptual framework on how IPRs might be linked to bilateral intra-industry trade. In other words, this paper answers a positive question of how the level of intellectual property rights induced market expansion, and market power effects are related to the horizontal and vertical intra-industry trade flows.

The paper is organized as follows. Section 2 provides basic elements of the proposed framework. Section 3 explains the link between horizontal IIT (HIIT) and intellectual property rights, which is further subdivided into demand side of HIIT and supply-side of HIIT. The association between IPRs and vertical IIT (VIIT) is explained in Section 4; this association is also subdivided into demand-side of VIIT and supply-side of VIIT. Finally, Section 5 contains the conclusions.

\section{The Conceptual Framework: Elements}

The intuitive framework of this paper assumes there are only two countries in the world: Country A and Country $\mathrm{B}$, and that they are identical, except for the degree of IPR protection ${ }^{1}$. Initially, the two countries conduct IIT in the absence of any IPRs protection; however, IPRs in Country B are then strengthened. Furthermore, it is assumed that the two countries conduct a bilateral vertical IIT in an automobile industry and also a bilateral horizontal IIT in a textile industry ${ }^{2}$. Accordingly, it is assumed that Country A exports car suspensions to Country B and imports finished cars from Country B (i.e. VIIT in automobile industry). For the bilateral HIIT in the textile industry, it is assumed that both countries exchange finished men's suits (i.e. HIIT in the textile industry).

The "intuitive conceptual framework" introduces a demand-side approach and a supply-side approach in explaining the link between IPRs and intra-industry trade flows. The supply-side approach explores how a country's IPRs affect its own exports (supply). In contrast, the demand-side approach examines the effect a country's IPRs have on its own imports (demand). Therefore, in determining bilateral trade flows in a two-country world, the demand approach posits that bilateral trade flows may also increase or decrease due to improvements in IPRs in the importing destination country, while the supply-side approach states that the bilateral trade flows may increase or decrease due to strong IPRs in the exporting country.

In the presented "intuitive framework", the relationship between IPRs and IIT flows is explained in terms of HIIT and VIIT. Then, the relationship is subdivided into the demand-side approach and the supply-side approach as shown in Figure 1 below.

\section{Horizontal IIT}

Horizontal intra-industry trade is defined as the exchange of similar goods that are simultaneously exported and

\footnotetext{
${ }^{1}$ Since both countries are identical, this argument can be equally applied to the counter trading partner country.

${ }^{2}$ The definition of vertical and horizontal IIT is based on the organization of production process as in the studies by Thom and McDowell (1999); Kandogan (2003a, 2003b); and recently by Yomogida (2004) [4]-[7].
} 


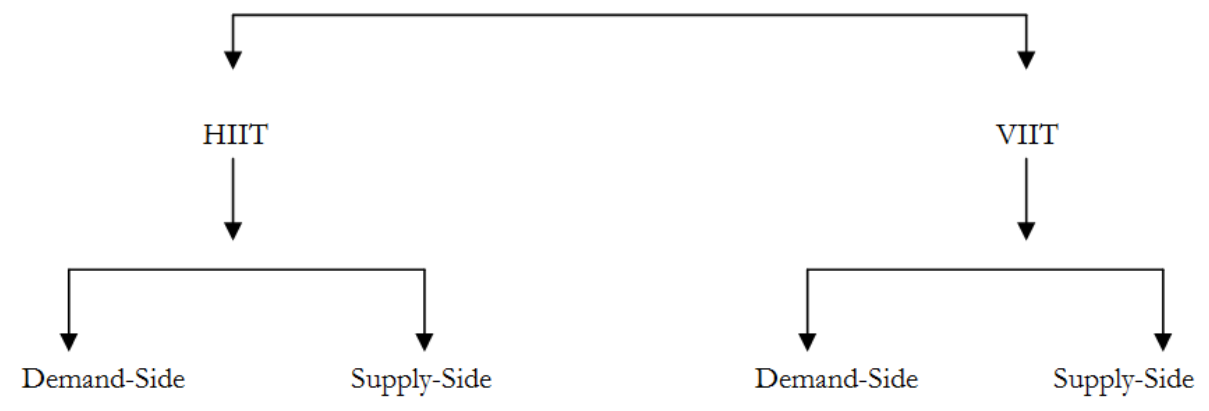

Figure 1. IIT-IPRs intuitive conceptual framework. Source: Author’s own construction.

imported at the same stage of production; it is mainly due to product differentiation [5] [6]. In the given HIIT example, it was assumed that Country A and Country B simultaneously export and import similar but differentiated men's suits, exhibiting the characteristics of monopolistic competitive market goods.

Throughout the presented "intuitive conceptual framework", it is assumed that Country B has strengthened its IPRs. Then investigate how Country A reacts to the strong IPRs in Country B, given that both countries are simultaneously exporting and importing similar goods i.e. conducting IIT is investigated ${ }^{3}$. To keep this analysis clear and simple, it is assumed that there are no artificial trade barriers (e.g. tariffs and quotas), and the export is the only mode of serving a foreign destination market (i.e. no FDI nor licensing). In terms of HIIT, the demand-side approach of HIIT will be explained first, and then followed by the supply-side approach of HIIT.

\subsection{Demand-Side of HIIT}

The existing literature on one-way trade (not IIT literature) and IPRs protection could be viewed in general, as pertaining to the case of horizontal intra-industry trade flows. The reason is that the existing IPRs-one-way trade literature implicitly assumes that there is local competition in the destination country for the imported foreign goods. Therefore, the locally produced goods (whether produced illegally or not) in a destination country are competing with the imported foreign goods. This may be true whether the local firms in the destination (importing) country are exporters or not. This implies that the foreign exporting firms that export to a destination country still have to worry about the prospect of local firms in a destination country pirating their own goods, even if the local firms are not exporters (i.e. the case of one-way trade only). Therefore, the locally produced goods in the destination country are implicitly assumed to be substitutes, to a certain extent, for the foreign imported goods.

The existing literature that has only examined the effects of IPRs on import demand has focused on two key concepts: market expansions and market power. The former occur when tightening the degree of IPRs protection in, say, a destination country attracts foreign exporting firms to increase their export to the destination country, whereas market power occurs when foreign exporting firms choose to reduce their sales to the destination country as a response to the monopoly power that may be associated with the existence of such high degrees of IPRs protection in the destination country.

Since Country A and Country B conduct bilateral HIIT, then it is plausible that both countries have, to some extent, the same imitative ability (IMIT) to produce similar goods (i.e. goods that are produced at the same stage of production; HIIT). The imitative ability of a country means its ability to obtain the requisite knowledge to copy and reproduce technology and goods produced elsewhere. It is different from the concept of IPRs protection per se. The latter means the general measurement of country compliance to general rules and regulations of intellectual property rights.

This suggests that there is an interaction between the IPRs protection of a country and its imitative ability (IMIT). This interaction is referred to in the literature as imitation threat, and can be measured jointly by the IPRs variable and imitative ability variable (IMIT) [8]. Considering two forms of imitation threat, weak vs. strong, a country with weak imitation threat is characterized by strong IPRs protection and weak imitative ability, whereas a country with strong imitation threat is characterized by weak IPRs protection and strong imitative

\footnotetext{
${ }^{3}$ Since both countries are assumed to be identical, and then the choice of which country has strong IPRs and which react to it is not important Therefore, the proposed argument can also be exactly applied to the counter trading partner country.
} 
ability.

Let us now focus the discussion on market power and market expansions in relation to bilateral horizontal IIT between Country A and Country B.

With respect to the market power effects of IPRs protection, introducing IPRs in Country B implies that Country A men's suits sold in Country B become more differentiable (e.g. by a brand name). Ceteris paribus, this may cause the elasticity of demand for foreign made men's suits to fall and thus increase the market power of Country A firms exporting to Country B. The market power of Country A firms would be reflected in higher prices of Country A men's suits sold in Country B. The extent of the increase in market power enjoyed by firms in Country A will also be expected to depend on a variety of factors in country B, in addition to the strength of IPRs. These factors may include market structure; competition polices and demand elasticity (Maskus, 2000 $[2])^{4}$. However, the point to be emphasized is that, although the market power of firms in Country A can be weakened by the aforementioned factors, market power can be exercised by Country A firms in response to strong IPRs in Country B.

Taking into account the threat of the imitation variable (interaction between IPRs and imitative ability), one might expect that the market power might be important when a foreign exporting firm trades with a destination country that is characterized by weak threat of imitation (by definition a weak threat of imitation country poses strong IPRs protection and weak imitative ability). The reason is that a foreign exporting firm might find it possible to react monopolistically when it exports its goods to a country with high IPRs protection and weak imitative ability.

The market expansions effects in the context of HIIT demand side approach can be explained. The demand for (i.e. imports of) Country A men's suits in Country B may increase, as Country B becomes an imitation free country because of the strong IPRs in Country B. The reduction in Country B competition therefore increases the demand for Country A imports of the horizontally intra-industry trade goods. This may happen because strong IPRs in Country B reduce the ability of local firms in Country B to imitate the imported men's suits of Country A. Therefore, this shifts the demand faced by Country A firms outward, and increases the imports from Country A. It is clear that the same prediction applies to the analysis of one-way trade and IPRs protection. Furthermore, taking into account the threat of the imitation variable, it might be expected that the market expansions effect is important when a foreign exporting firm is trading with a destination country that is characterized with strong threat of imitation. The reason is that these countries have, by definition, high imitative ability; therefore, if the foreign exporting firms decided not to export to the destination country with strong imitative ability, the destination country may end up imitating the foreign products.

Overall, the expected demand side effects of IPRs protection on bilateral HIIT is the same as the effect of IPRs on one-way trade and can be summarized in Table 1.

\subsection{Supply-Side of HIIT}

To address the question of how improvements in IPRs protection in a country affect the country's own exports (i.e. supply), factors that affect production of local firms and thus overall export performances of the country (which are also influenced by IPRs protection) are to be examined. Indeed there is a large body of literature on factors that affect a firm's export performance in a country, such as size of a firm, age of firm, whether a firm is part of a business group, its marketing and financial capabilities (i.e. micro-determinants). Similarly, there are also macroeconomic variables, such as the exchange rate, income level of partner countries, historical links, and economic integration with partner countries that are also known to be important for competitiveness and thus exports. However, the discussion here will focus only on factors that influence the overall export performance of a country which is simultaneously stimulated by a strong local IPRs protection. Therefore, factors such as domestic R\&D, and inward FDI, which are stimulated by IPR protection and are potentially important determinants of export performance, will be considered.

As for the domestic R\&D and local IPRs protection, it is known that one of the primary objectives of the IPRs system in a country is to protect inventors from being imitated and hence to provide them with an incentive to perform more domestic research and development. Accordingly, ceteris paribus, strong local IPRs protections provide incentives to local inventors whilst generally permitting knowledge diffusion, and thus more inventions. With more output due to innovations, the excess is expected to be exported (supplied to) abroad. As regards in-

${ }^{4}$ For simplicity and to keep focused on the main aim of this discussion, these possible factors, which might affect pricing behavior, are excluded from the present discussion. 
Table 1. A Horizontal IIT (demand-side approach).

\begin{tabular}{cccc}
\hline \multirow{2}{*}{ Variables } & \multicolumn{2}{c}{ Bilateral Horizontal IIT } & Overall Effects on HIIT \\
\cline { 2 - 3 } & Market Power & Market Expansions & Ambiguous $(-$ or +$)$ \\
IPRs Variable & Yes $(-)$ & Yes $(+)$ & $(-)$ \\
Weak Threat of Imitation Variable & Yes $(-)$ & No & $(+)$ \\
Strong Threat of Imitation Variable & No & Yes & $(+)$ \\
\hline
\end{tabular}

Note: "Yes" indicates that the expected effect is possible. The negative (positive) sign indicates that the effect is negatively (positively) correlated with bilateral HIIT. The imitation threat of a country is measured jointly by its IPRs protection and imitative ability.

ward FDI and strong local IPRs protection, it might be speculated that strong local IPRs protection opens up a new opportunity for foreign investors to invest in a country with strong IPRs protection, and again, the excess output is expected to be exported (supplied) abroad. The arguments of inward FDI can be extended to the case of outsourcing and licensing; however, for simplicity the FDI is used as a representee for both the outsourcing and licensing.

Providing a full analysis of how domestic R\&D and inward FDI are influenced by strong domestic IPRs protections in promoting the export performance of a country is complicated by many factors including the dynamic nature of R\&D and inward FDI. In addition, the direction of causality between IPRs and variables of concern might be a matter of concern as it is not clear what causes what. For instance, does domestic R\&D lead to a need for more patents and thus demand for stronger IPRs protection, or is it that strong IPRs protection encourages more of R\&D? Furthermore, the potential of endogeneity between these two factors (R\&D, inward FDI) and IPRs protections may exist. This is because it is sometimes difficult to disaggregate the effects of the IPRs system in export performance from other factors that may also have an impact on the overall exports, for instance, factors such as the political stability of a host country with strong IPRs and the cost effectiveness of investing in a host country with strong IPRs protection.

Therefore, to carry out such analysis in a simple intuitive framework, further assumptions are needed. Assumptions include, firstly, the static natures (not dynamic) of the variables of concern are to be considered. Secondly, the causality is assumed to run from IPRs protection to R\&D and inward FDI, and then to exports (supply). Finally, endogeneity between these two factors (R\&D, inward FDI) and IPRs protections is not important, and thus can be ignored for the time being. These assumptions will not destroy the main objective of this analysis in this paper; however, they make the analysis more compact and easy to follow.

The improvement of IPRs in County B affects its own exports (supply) of horizontally intra-industry traded goods. In terms of HIT and in the context of the on-going HIIT example, what is of concern here is to answer the question of how improvements in IPRs protection in Country B affect its own exports (i.e. supply) of men's suits to Country A, keeping all other factors constant. Put differently, would improved IPRs protection in Country B cause local firms in Country B to increase the quantity and variety of goods they produce and then export surplus to Country A or not?

It is worth noting that traditional market power and market expansion concepts used previously in the demand-side approach are not explicitly applicable to the case of the proposed supply-side approach. This is because these terminologies are typically used to explain how a foreign exporting country reacts to a change of IPRs in an importing destination country. However, in the supply-side approach, what is of interest is how a change in the local IPRs in a country affects its own exports (supply) only.

The previous discussion revealed that improvements in IPRs in Country B might lead to more domestic R\&D and inward FDI in Country B. However, would the domestic R\&D, influenced by strong local IPRs protection, induce exports of men's suits (i.e. HIIT goods in the given example) from Country B to Country A? The short answer is that it depends on the output of domestic R\&D in men's suits. And, it is assumed that as a result of strong domestic IPRs protection in Country B, the output of domestic R\&D leads to production of greater quantity, new varieties, and better qualities of men's suits. Then, ceteris paribus, if the new domestic production exceeds local demand, then the surplus will be exported (supplied) to Country A. However, this also suggests that if the quantity of new domestic production stimulated by improvements in IPRs is only to replace the shortage of goods available in the domestic market (or to replace the imported men's suits), then there may not be enough men's suits for export, so export will not be affected; at least, for low levels of IPRs ${ }^{5}$.

${ }^{5}$ This argument might also be equally extended and applied to the case of inward FDI. 
In terms of supply-side effects and taking into account the effect of the imitation threat variable (IPRs and imitative ability) on bilateral HIIT, it is expected that a country posing a strong imitation threat (i.e., weak IPRs and strong imitative ability) might discourage domestic innovative firms from entering the domestic market as their products can be internally pirated by other domestic firms. The reverse is also expected to be true for those countries with a weak threat of imitation.

The relationship between exports of HIIT goods and improvement in IPRs in the context of the supply-side approach is explained diagrammatically in Figure 2. In Figure 2, the value of IIT is measured in (\$) and placed on the vertical axis (imports on LHS and exports in RHS). The improvements in IPRs is measured by a scale (say) from 0 to 10 and placed on the horizontal axis. As the focus is on the supply-side only, the demand curve is not important for the moment, thus it is not shown. The supply curve is upward sloping as it represents the supply-side approach when exports react positively to improved IPRs because of increased domestic R\&D and inward FDI. Figure 2 shows that the initial improvements in IPRs protection have no effect on exports. This is because the initial increase in IPRs is assumed to attract more domestic R\&D and inward FDI to serve only the local market. This is sensible because the new domestically produced goods initially either produced to replace the shortage of the existing imitated goods in the local market, and/or replace the legally imported goods that are now produced locally because of (say) inward FDI and improved domestic R\&D. However, after a period of time IPRs reach a certain stage (i.e. at point B in Figure 2) when the improved IPRs will start to stimulate exports, as there will be sufficient surplus for export (supplied).

To sum up, the improvement of IPRs in a country may cause its overall export performances to increase due to improved domestic R\&D and/or increased inward FDI. However, this might not happen instantly as it depends on whether the initial local demand is satisfied or not. Table 2 summarizes the overall effect of strong IPRs on bilateral HIIT in terms of the supply-side approach.

\subsection{Supply-Demand Synthesis}

The demand-side approach states that strong IPRs in a country may increase or decrease its demand (imports) from foreign countries. On the other hand, the supply-side approach states that strong IPRs in a country may increase its own exports (supply) to foreign countries. It is apparent that either approach can be used independently to explain the effects of strong IPRs on one-way trade flows as posited by the existing IPRs-trade literature.

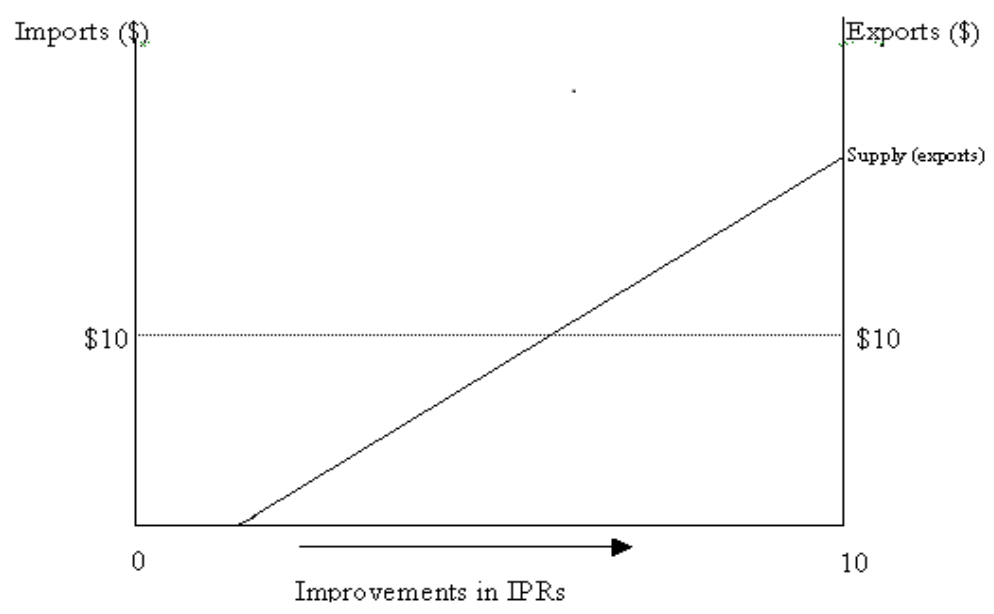

Figure 2. Supply-side approach. Source: Author’s own construction.

Table 2. Horizontal IIT and IPRs protection (supply-side approach).

\begin{tabular}{ccc}
\hline \multicolumn{2}{c}{ Bilateral Horizontal IIT Flows } & The Overall Effects \\
\hline Increase & Decrease & Increases after Certain Stage $(+)$ \\
Yes $(+)$ & No & \\
\hline
\end{tabular}

Notes: "Yes" indicates that the expected effect is possible, and the positive sign $(+)$ indicates that the effect is positively correlated with bilateral HIIT. 
However, in explaining bilateral intra-industry trade flows, the two approaches must be used simultaneously. The need for the use of both approaches simultaneously in determining the bilateral IIT flows arises because of the way IIT is defined and measured. The total value of bilateral intra-industry trade in an industry for a particular country is defined as matched trade in an industry [5] [6]. The matched trade implies simultaneous matching of exports and imports within an industry. Therefore, using the demand (imports) or supply (exports) approaches separately would not allow for the existence of matched trade (i.e. IIT). The reason is that the demand-side approach only explains the imports of a country with strong IPRs and the supply-side approach only explains the exports of a country with strong IPRs. Yet, the occurrence of the bilateral intra-industry trade in a particular industry requires a value of imports to correspond with the value of exports in the given industry.

To illustrate the concepts of matched exports and imports (IIT), a demand-side curve is added to Figure 2 to produce a new figure that contains both supply and demand curves (i.e. Figure 3). Therefore, in the context of the combined supply and demand approaches, the possible outcomes of improving IPRs protection in a country are shown in Table 3 and Figure 3.

The table above reveals that the only case in which bilateral intra-industry trade is ultimately expected to increase is when there is an increase in (say) demand that is matched by an increase in supply.

The shaded area in Figure 3 corresponds to a situation where exports are matched by imports and hence IIT. As explained previously, the supply-side curve is upward sloping to indicate that it is positively related to the improvement of IPRs protections such that an improved IPRs protection in a country augments its local R\&D and inward FDI, thus enhancing its exports (supply). However, as mentioned before, the initial improvements in IPRs may have no effect on exports. This is because the newly produced goods at first serve the domestic market only. The demand-side curve is downward sloping to indicate that improved IPRs may cause a fall in demand for the imported foreign goods because of market power effects. The shaded area is the matched exports and imports (i.e. IIT) when exports and imports equal each other at $\$ 10$ million as shown at point $\mathrm{X}$ in the above figure.

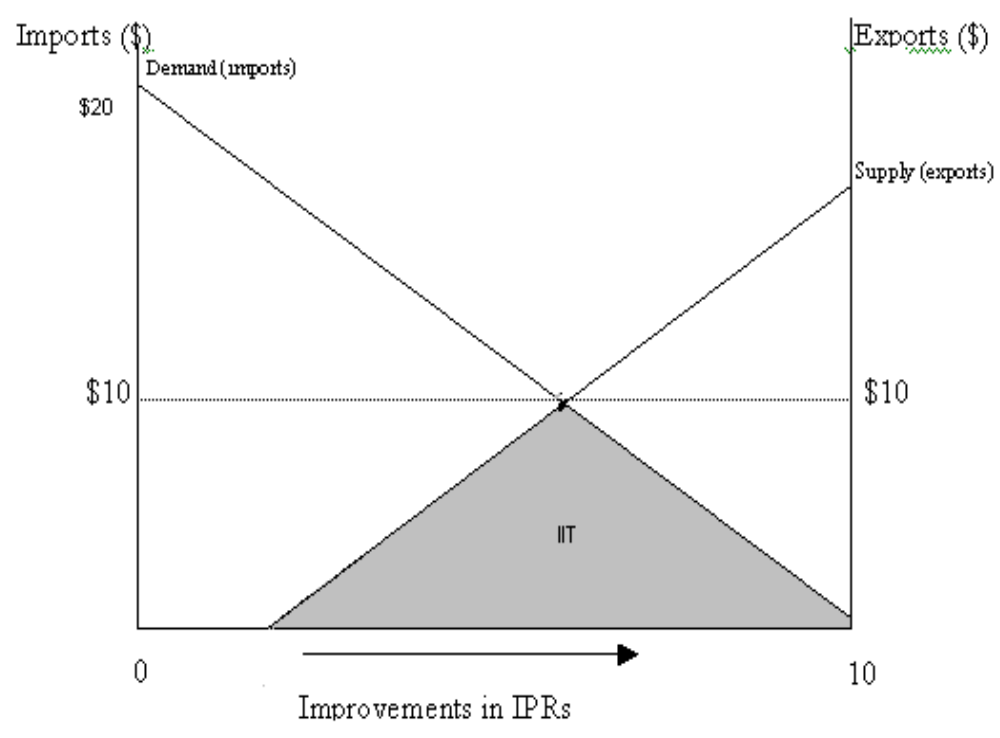

Figure 3. Supply and demand approaches ${ }^{6}$ (supply is increasing and demand decreasing with IPRs). Source: Author's own construction.

Table 3. Possible outcomes of combing supply and demand approaches.

\begin{tabular}{cccc}
\hline & Demand (Imports) & Supply (Exports) & Ultimate Effect on IIT \\
\hline Case 1 & Decrease (M.P.) & Increase & Indeterminate \\
Case 2 & Increase (M.E.) & Increase & Increase \\
\hline
\end{tabular}

Note: M.P. stands for market power, and M.E stands for market expansions.

${ }^{6}$ It is worth noting that this figure is not to be interpreted as a typical demand and supply figure, and therefore the intersection is not an equilibrium towards which the economy naturally adjusts. 
Case one in Table 3 is illustrated in the above figure when demand is decreasing function of IPRs and supply is increasing function of IPRs. At the outset, Country B imports (demands) $\$ 20 \mathrm{~m}$, but does not export because the initial improvement in IPRs (say) attracts FDI to only serve the local market (by assumption); however, imports (demands) fall due to market power. Then when IPRs reaches a certain stage (at point B in the figure below), IPRs will then stimulate an increase in exports. Imports will then keep decreasing and exports increasing as IPRs improve, and, in turn, increase the overall value of IIT until the IIT value eventually reaches $\$ 10 \mathrm{~m}$ at point X. After this point, any increase in IPRs will result in a decrease in imports and an increase in exports, but will have negative effects on the IIT value as the increase in exports is not exactly matched by imports, so the value of IIT decreases. In this case (case one in Table 3) IIT is rising at the beginning until point X, and then falling as IPRs improve, causing the IIT value to fall. Briefly, when demand is decreasing as a function of IPRs and supply is increasing as a function of IPRs, the ultimate effect on IIT values is indeterminate as it may increase and then decrease (see case one in Table 3).

Figure 4 shows a case in which both demand and supply curves are increasing as a function of IPRs protection. This is a possible case because the demand can increase due to market expansions, and supply can increase due to an increase in exports induced by improved IPRs resulting from (say) inward FDI or domestic R\&D. In this case, Figure 4 illustrates that the values of imports and exports increase as IPRs increase and thus increase the value of IIT out (case two in Table 3).

To sum up, there is no prior expectation of whether the improved IPRs protection in a two-country world would lead its IIT value to increase or not, because this depends on whether demand is increasing (market expansions) or decreasing (market power) function of improvement in IPRs protection. However, if demand and supply are both increasing as a function of improvement in IPRs protection, then the value of IIT is expected to increase [9].

\section{Vertical IIT}

Vertical intra-industry trade (VIIT) refers to the simultaneous exports and imports of goods in the same industry but at different stages of production. It is generally thought to be due to varying factor intensities within an industry [5] [6]. It can also be viewed as an exchange of intermediate goods and final goods that use the intermediate goods for their production [7].

Demand and supply sides of VIIT will be explained in the context of the ongoing VIIT example (i.e., automobile industry). The analysis begins with the demand-side and is then followed by the supply-side.

\subsection{Demand-Side of VIIT}

The existing literature reveals little about the link between IPRs protection and VIIT flows. Therefore, prior to investigating the conventional market power and market expansions' effects in terms of vertical intra-industry

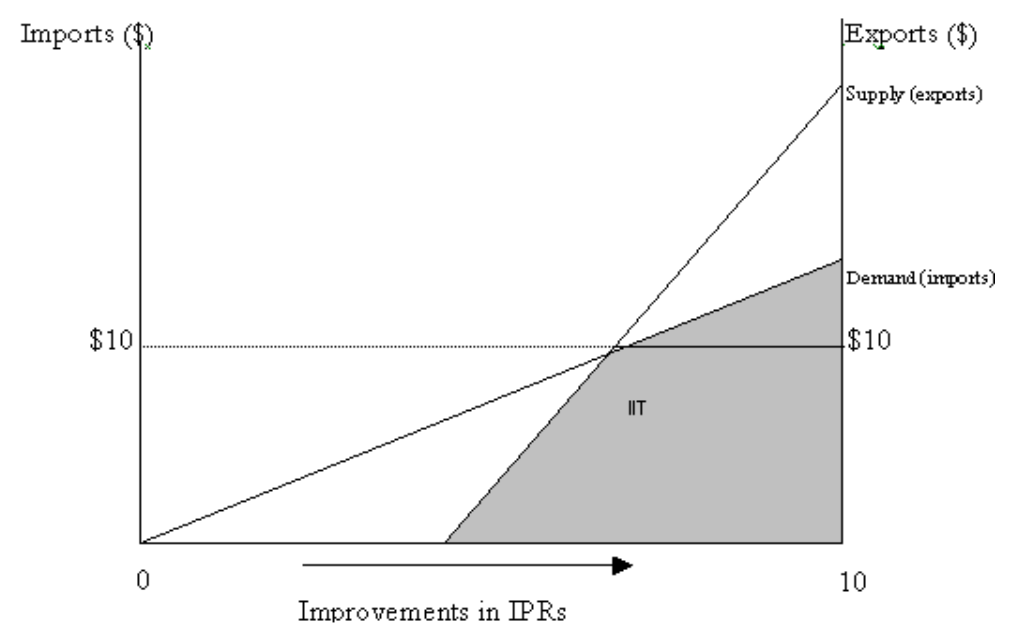

Figure 4. Supply and demand approaches (supply and demand increasing with IPRs). Source: Author's own construction. 
trade using the demand-side approach, the nature of bilateral vertical intra-industry trade flows between two countries will be analyzed.

The nature of bilateral vertical intra-industry trade flows between two countries will be discussed in reference to the on-going automobile example representing VIIT in this context, in which it is assumed that Country A does not produce finished cars as it only exports car suspensions to Country B; these suspensions are used to produce finished cars in Country B. Then Country B's finished cars are exported to Country A. Accordingly, this type of trade is considered, by definition, a vertical intra-industry trade in the automobile industry.

In view of the fact that the vertical IIT in a given industry is defined as exchanging goods that are produced at different stages of production due to different factor intensity or due to technological differences within an industry, a comparative advantage theory may play a role in explaining the existence of VIIT.

Furthermore, as mentioned previously, vertically intra-industry traded goods can be thought of as trading intermediate goods for final goods. This implies that vertically intra-industry traded goods can be considered as complements unlike horizontally intra-industry traded goods which can be considered, to some extent, as substitutes. This characteristic of vertically intra-industry traded goods has an interesting implication in regard to cross-price elasticity of demand when discussing the relationship between IPRs and VIIT flows. It is apparent from the given VIIT example that the car suspensions produced in Country A are used as input to produce finished cars in Country B. This implies that the two goods are indeed complement goods. From microeconomic theory, it is known that the cross price elasticity of demand which measures the responsiveness of changes in the quantity demanded to changes in the price of a different good is negative for complement goods.

It is worth noting that the meaning of complement goods (in consumption) in the case of vertically intra-industry traded goods is different from the ordinary textbook meaning of complement goods. In the latter, the two complement goods are generally referred to as physically finished final goods (e.g. camera film \& camera), whereas in the former, the two goods are not (e.g. car suspensions \& car). Therefore, in the case of VIIT goods in the given automobile example, when the price of one good (the intermediate good) increases, one may expect the supply (not demand) of the other good to decrease. In the context of the given VIIT example, if the price of car suspensions rises, the supply of finished cars is expected to decline, assuming that both car suspensions and finished cars are traded in the one market.

Although the existing literature did not (explicitly) incorporate the vertically intra-industry traded goods into concepts of market power and market expansions effects, these concepts can be employed in this type of trade in the context of the given VIIT example and its associated assumptions as follows:

First, there is the possibility of market power effects for the case of VIIT. Conventionally, as mentioned before, strong IPRs protection in Country B leads firms in Country A to export less of their goods (i.e. car suspensions) to Country B because strong IPRs in Country B grant a monopoly power over the protected goods. This arises because strong IPRs in Country B cause the elasticity of demand facing Country A's exporting firms to fall. Although strong IPRs in Country B give Country A more market power in exporting its VIIT goods, in practice Country A, may not exercise its monopoly power independently. In other words, while Country A exporting firms are able to set a monopoly price (one above competitive price in a downward sloping demand curve) in Country B as a reaction to its strong IPRs, they may not be interested in doing so. The reason is that the two vertically intra-industry traded goods are complements in the extended joint market (that includes both Country A and Country B). Therefore an increase in the price of one good (i.e. car suspensions) reduces the supply of the other good (i.e. finished cars). This will have inverse effects on exporting firms in Country A as well, which may not be desirable. This is because reduction in demand for finished cars indirectly means a demand reduction for car suspensions as well. This is happening because the car suspensions produced by Country A are indeed used as input to finished cars in Country B. This implies that, in the joint market of Country A and Country B, the demand for car suspensions is derived from the demand for finished cars as well.

It can also be argued that, taking into account revenues of Country A exporting firms, the increase in price of car suspensions produced by Country A due to market power might outweigh the reduction in the quantity demanded by Country A, and therefore, market power is still a possible option to be used by Country A firms to gain a monopoly rent. However, this depends on two interrelated factors: firstly, how elastic the cross price elasticity of demand is and the time lag for an increase in the price of car suspensions to cause a reduction in demand for finished cars. In the case that cross-price elasticity of demand is too low and it takes long for an increase in the price of car suspensions to be reflected in the demand for finished cars, then firms in Country A may be able to exercise their monopoly power, reaping monopoly rents (albeit for only a short period of time). 
Otherwise, ceteris paribus, it can be speculated that it is not of interest to exporting firms in Country A to react monopolistically to strong IPRs in Country B.

Considering the possibility of market expansion effects, strong IPRs in Country B may lead to a higher demand for the car suspensions produced by Country A because strong IPRs in Country B lower the possibility of infringement by local firms in Country B, and therefore increase the demand for Country A's car suspensions in Country B (i.e. Country A exports to Country B). The possibility of market expansion effects can also be viewed from the fact that the two vertically intra-industry traded goods are complements. Therefore, if Country A exports more car suspensions to Country B, then, ceteris paribus, Country B might produce more of its finished cars and export some of these finished cars back to Country A. Therefore, market expansions effects are a possible outcome of strong IPRs in Country B. Overall, the expected effects of IPRs protection on bilateral VIIT can be summarized as indicated in Table 4.

As far as the threat of the imitation variable (represented by IPRs \& imitative ability) is concerned, it is expected that the demand for vertically produced goods will increase in the case of a weak imitation threat because the destination country (i.e., recipient country) poses strong IPRs and weak imitative ability, thus encouraging the foreign exporting firms to export to a destination country with weak imitation threat.

\subsection{Supply-Side of VIIT}

In the context of given vertical IIT goods in the on-going automobile example, the supply side approach means that how Country B numbers of its finished cars supplied to Country A might be affected by strengthening its own IPRs protection, keeping all other factors constant. Put differently, would strong IPRs in Country B affect its own exports of finished cars to Country A?

Taking into account the given assumptions in the on-going VIIT example, and keeping all other factors constant, this suggests that higher IPRs in Country B increase the likelihood that Country B can produce more of its finished cars and export the surplus to Country A. In other words, due to the increase in the domestic R\&D in Country B, there is a good probability that there would be improvements in the produced finished cars either in quantity and/or quality. This will increase the likelihood of Country B exporting more of its finished cars to Country A. However, if the domestic R\&D in Country B is directed toward producing car suspensions that are usually imported from its partner country (i.e. Country A), then the car suspensions imported by Country B from Country A might decrease. This may cause an inverse effect on the bilateral VIIT between Country A and Country B.

As far as inward FDI is concerned, stronger IPRs protection in Country B opens up new prospects for Country A firms to take advantage of the strong IPRs in Country B through FDI (i.e. inward FDI from Country B's point of view). In terms of the given vertical IIT example, due to the strong IPRs in Country B, firms in Country A now have an opportunity to invest directly in Country B. If Country A firms decide to invest directly in car suspensions in Country B, this implies that Country A's usual exports of car suspensions to Country B might decrease as the trade is now substituted by inward FDI that flows to Country B. This may have an inverse effect on the bilateral VIIT in the automobile industry between the two countries in question.

There is no prior expectation as to whether firms in Country A will be investing in car suspensions. This suggests that the strong IPRs in Country B do influence its inward FDI and domestic R\&D; however, the direction in terms of bilateral VIIT in the automobile industry is uncertain.

Table 5 summarizes the expected effect of a strong IPRs on bilateral VIIT in terms of the supply-side approach.

Table 4. Vertical IIT and IPRs protection (demand-side approach).

\begin{tabular}{|c|c|c|}
\hline & & $\begin{array}{l}\text { The Overall } \\
\text { Effects }\end{array}$ \\
\hline $\begin{array}{l}\text { Market Power } \\
\text { Effects }\end{array}$ & $\begin{array}{l}\text { Market Expansions } \\
\text { Effects }\end{array}$ & \multirow{2}{*}{ Ambiguous $(-/+)$} \\
\hline $\begin{array}{l}\text { Ambiguous } \\
\text { Effects (?) }\end{array}$ & Yes (+) & \\
\hline
\end{tabular}

Note: "Yes" indicates that the expected effect is possible, and the positive sign indicates that it is positively correlated with bilateral VIIT. "?” indicates the expected effect is ambiguous. 
Table 5. Vertical IIT and IPRs protection (supply-side approach).

\begin{tabular}{ccc}
\hline & Bilateral VIIT Flows & The Overall Effects \\
\hline Increase & Decrease & Ambiguous (?) \\
$?$ & $?$ & \\
\hline
\end{tabular}

Note: "?” indicates that the expected effect is ambiguously correlated with bilateral VIIT.

\section{Conclusion}

The main purpose of this paper has been to "intuitively" trace the relationship between the level IPRs protect-tions and bilateral intra-industry trade flows. The paper provided the first intuitive conceptual framework for modeling the relationship between level of IPRs and bilateral intra-industry trade flows. The intuitive model reveals that supply and demand side effects of IPRs are simultaneous and equally important in determining the level of the bilateral intra-industry trade. The proposed framework enables the researchers in the field to better explain the link between IPRs protection and bilateral intra-industry trade.

\section{References}

[1] Fink, J. and Braga, P. (1999) How Stronger Protection of Intellectual Property Rights Affects International Trade Flows. World Bank Working Paper, No. 2051. The World Bank.

[2] Maskus, K. (2000) Intellectual Property Rights in the Global Economy. Institute for International Economics, Washington, DC.

[3] Krugman, P. and Obstfeld, M. (2000) International Economics: Theory and Policy. 5th Edition, Sultan Qaboos University, Muscat.

[4] Thom, R. and McDowell, M. (1999) Measuring Marginal Intra-Industry Trade. Weltwirtschaftliches Archiv, 135, 48-61. http://dx.doi.org/10.1007/BF02708158

[5] Kandogan, Y. (2003) Reconsidering the Adjustment Costs of the Europe Agreements. Applied Economics Letters, 10, 63-68. http://dx.doi.org/10.1080/13504850210138478

[6] Kandogan, Y. (2003) Intra-Industry Trade of Transition Countries: Trends and Determinants. Emerging Markets Review, 4, 272-286. http://dx.doi.org/10.1016/S1566-0141(03)00040-2

[7] Yomogida, M. (2004) Vertical Intra-Industry Trade and Factor Proportions. Hitotsubash Journal of Economics, 45, 6778.

[8] Smith, P. (1999) Are Weak Patent Rights a Barrier to US Exports? Journal of International Economics, 48, $151-177$. http://dx.doi.org/10.1016/S0022-1996(98)00013-0

[9] Al-Mawali, N. (2005) Bilateral Intra-Industry Trade Flows and Intellectual Property Rights Protections: First Empirical Evidence. Applied Economics Letters, 12, 823-828. http://dx.doi.org/10.1080/13504850500358751 
Scientific Research Publishing (SCIRP) is one of the largest Open Access journal publishers. It is currently publishing more than 200 open access, online, peer-reviewed journals covering a wide range of academic disciplines. SCIRP serves the worldwide academic communities and contributes to the progress and application of science with its publication.

Other selected journals from SCIRP are listed as below. Submit your manuscript to us via either submit@scirp.org or Online Submission Portal.
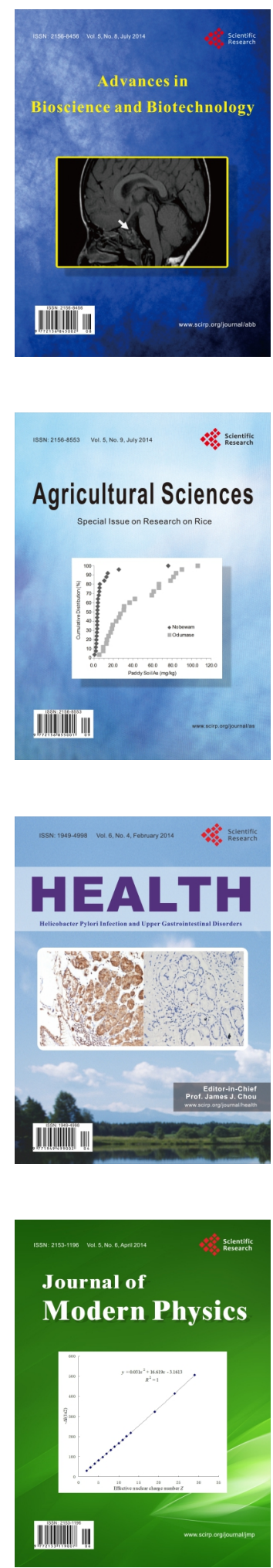
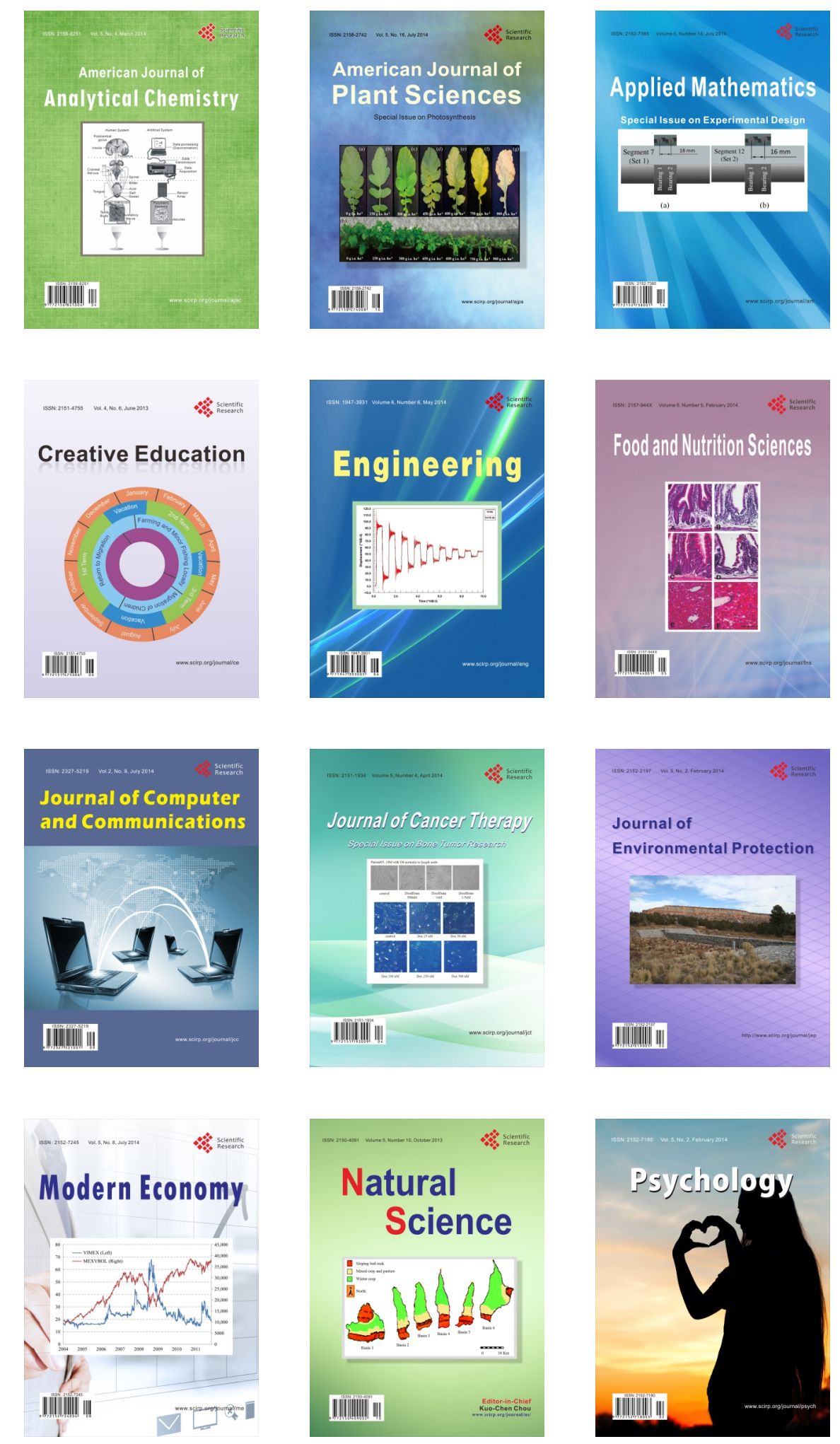